\title{
Raising Children: The Case for Government Intervention
}

Well-being is "the state of being happy, healthy, or prosperous," according to the Merriam-Webster Dictionary. The Early Years: Child Well-Being and the Role of Public Policy focuses on the well-being of children in the early years of their lives, from conception to approximately 9 years of age. Scientists in the fields of biology, psychology, and economics have a clear view of what outcomes (and trajectories) define a happy, healthy, and potentially prosperous child; they are discussed in this chapter. What is less clear is how to raise children in order to achieve these outcomes and who should be involved in that process. Why should the government be directly involved in the welfare of children?

The first reason is that children have a legal identity and a set of interests that are separate from their parents' and worth protecting. This notion of children's rights is relatively new but widely accepted. The United Nations Convention on the Rights of the Child is the most widely ratified human rights treaty, signed by 194 nations. However, historically, social programs have taken the needs approach, with children as beneficiaries of policies, and governments acting out of patronage and charity (see Box 1.1). Instead, the rights approach recognizes them as individuals with legal rights who are equal before any law and policy.

The second rationale for government involvement is that children that flourish in the early years are more likely to become productive citizens. An investment in a child's well-being is an investment that generates returns over the long term, and affects the prosperity and viability of society well into the future. Nevertheless, families are 


\section{Box 1.1 A History Lesson: Childhood and the Emergence of Children's Rights}

The concept of childhood has varied greatly through time and across cultures. The first modern study of childhood history was Philippe Ariès's Centuries of Childhood, published in 1962. In this influential book, Ariès argues that the term "child" started to develop its current meaning sometime between the seventeenth and twentieth centuries.

In modern society, it is generally accepted that "childhood" is a stage of life with certain traits that differentiates it from infancy and adulthood. In medieval society, children at the age of 7 acted-and were treated-as smaller versions of the adults around them; they were introduced to an adult world at a very early age through both labor and sexual exploitation.

The modern status of the child is concomitant with decreases in infant mortality, changes in the educational system, and the appearance of a separate isolated family unit. For most of human history, a significant proportion of infants did not survive to adulthood. Ariès (1962) argues that high mortality rates influenced parents' feelings of emotional indifference. These attitudes changed as survival became more likely.

The emphasis on the importance of education became widespread in the eighteenth century, thanks to the Enlightenment view that children needed to be educated to become good citizens. The development of schooling and its gradual extension and intensification were essential for defining a new idea of childhood, because schooling provided a transition phase between infancy and adult life (Clarke 2004).

An important precedent of child protection was the Poor Relief Act (1601) in Elizabethan England, which, for the first time, made poor children the responsibility of the parish. Among other things, the law established that pauper children would become apprentices. For the next three centuries in England, the parochial overseers of the poor took responsibility for the welfare of children whenever parenting failed or was absent.

While a new notion of childhood was emerging during the eighteenth century, the process of industrialization intensified the exploitation of many children. Although children always worked in preindustrial society, the emergence of the factory system made things worse for working children: many of the tasks they did were dangerous, and work conditions were unhealthy. This situation led to a relatively new notion during the nineteenth century: the child as the object of pity or philanthropy.

A growing number of reformers, alarmed at the conditions in which children were toiling in factories, worked to enact legislation that would 
control these practices. Even in the laissez faire atmosphere of Victorian Britain, it was accepted that childhood was a period of life in need of protection and that it was appropriate for the state to intervene on behalf of children (Lowe 2004). This was probably the first time the state accepted ultimate responsibility for protecting the well-being of children.

By the end of the nineteenth century, while poverty and illness was still frequent among children, the idea of children as the focus for policymaking had firmly taken root, paving the way for the twentieth century to become-as Ellen Key noted in her 1909 book- "the century of the child." In her book, Key imagines the century as a period of intense focus around the rights, education, and well-being of children.

During the twentieth century a clear view emerged that children's welfare is not merely a family responsibility: children are increasingly viewed as the responsibility of the state, which intervenes in their education, health, and upbringing in ways designed to improve national well-being by developing its future citizens.

This paradigm shift is reflected in some landmarks in children rights. In 1924, the League of Nations adopted the Geneva Declaration on the Rights of the Child. This was the first (nonbinding) historical text that recognized specific rights for children. The United Nations Fund for Children (UNICEF) was created in 1946. Following the Declaration of the Rights of the Child in 1959, childhood became a central issue in international cooperation programs and children began to be seen as having rights. In 1989, 140 states signed the Convention on the Rights of the Child. ${ }^{1}$

understandably more concerned with their needs today than with those of society tomorrow. The danger that the focus of child rearing will be biased much more toward the needs of the present than the future is another reason why public policy may have an important role to play in children's welfare.

\section{Child Development: A Long and Winding Road}

The foundations of child well-being start well before birth. During pregnancy, the fetus develops through a number of processes. In the first trimester, the formation and differentiation of organs takes 
place. In the second trimester, the fetus undergoes major cellular adaptation and increases in body size. Finally, during the third trimester, the organ systems mature and ready themselves for life outside the mother (Mullis and Tonella 2008).

The process of child development starts once the baby is born; it can be described as "the psychological and biological changes that occur as a child transitions from a dependent infant to an autonomous teenager" (Fernald and others 2009). These changes include physical development (changes in the size, shape, and physical maturity of the body, including physical abilities and coordination) and the development of language/communication skills (learning and using language), cognitive skills (the ability to reason, solve problems, and organize ideas), and socioemotional skills (gaining a sense of self, the ability to empathize and express feelings, and how to interact with others).

Child development is hardly a linear process in which outcomes change or progress smoothly from one stage to another. Rather, development accelerates and decelerates at different ages and stages. However, the development process is cumulative and events occur during predictable time periods. As a result, lack of development in certain areas or at certain points in time may have permanent consequences and may affect the well-being of an individual over her entire life cycle. The discussion that follows provides examples of how this cumulative, nonlinear process unfolds for many of the outcomes related to children's well-being and development.

Physical development: The rapid physical growth experienced during early childhood is captured by several anthropometric measures including length/height-for-age, weight-for-age, and head circumference. These measures represent important markers of physiological growth and are typically used as proxies for well-being. The World Health Organization (WHO) has created international standards that assess the growth and development of children from birth to age $5 .^{2}$ In general, children grow very rapidly in the first 6 months of life. At birth, the median child ${ }^{3}$ is 49.5 centimeters long, weighs 3.25 kilograms, and has a head circumference of 34.2 centimeters. ${ }^{4}$ Growth accelerates during the first 2 months of life and continues at a declining rate thereafter. 
Studies have shown that weight, height, head circumference, and growth pattern, particularly during the period of intrauterine growth and the first two years of life, are good predictors of outcomes later in life. Low gestational growth and low early childhood height-for-age predict short adult stature (Victora and others 2008). ${ }^{5}$ Longitudinal studies for developing countries show that growth failure in the first two years of life is associated with poor cognitive and other educational outcomes (Hoddinott and others 2013).

The process of physical development also includes motor skills (the ability to control the use of muscles). First, children learn to sit without support. This is typically followed by crawling on hands and knees, standing without assistance, walking with assistance, standing alone, and finally walking alone (WHO Multicentre Growth Reference Study Group 2006). Children acquire these developmental milestones during predictable time periods. ${ }^{6}$ For example, most children learn to sit without support between 4 and 9 months and are walking alone by 17 months.

Language/communication: Children's language development begins long before they utter their first word (Bloom 1998) and develops differently from one year to the next. Children babble at 2-4 months and make noises and try new and different sounds at 4-6 months. They point and gesture at around 12 months and say their first words and sentences in the first two years. They finally experience an explosion of words between ages 2 and 3 years (Woodward and Markman 1998). At 3-4 years, children speak well in sentences and are able to chant rhymes and enunciate clearly enough to be understood. As children move into the preschool years, indicators of language development include children's production and understanding of words, their ability to tell stories and identify letters, and their familiarity with books.

Reading is a complex developmental challenge that is related to other developmental processes, including attention, memory, language, and motivation (Snow, Burns, and Griffin 1998). Standardized tests of children's vocabularies and their knowledge of letters and print at the start of school are good predictors of their reading scores throughout childhood (Powell and Diamond 2012; Wasik and Newman 2009). Table 1.1 describes an example of the cumulative 


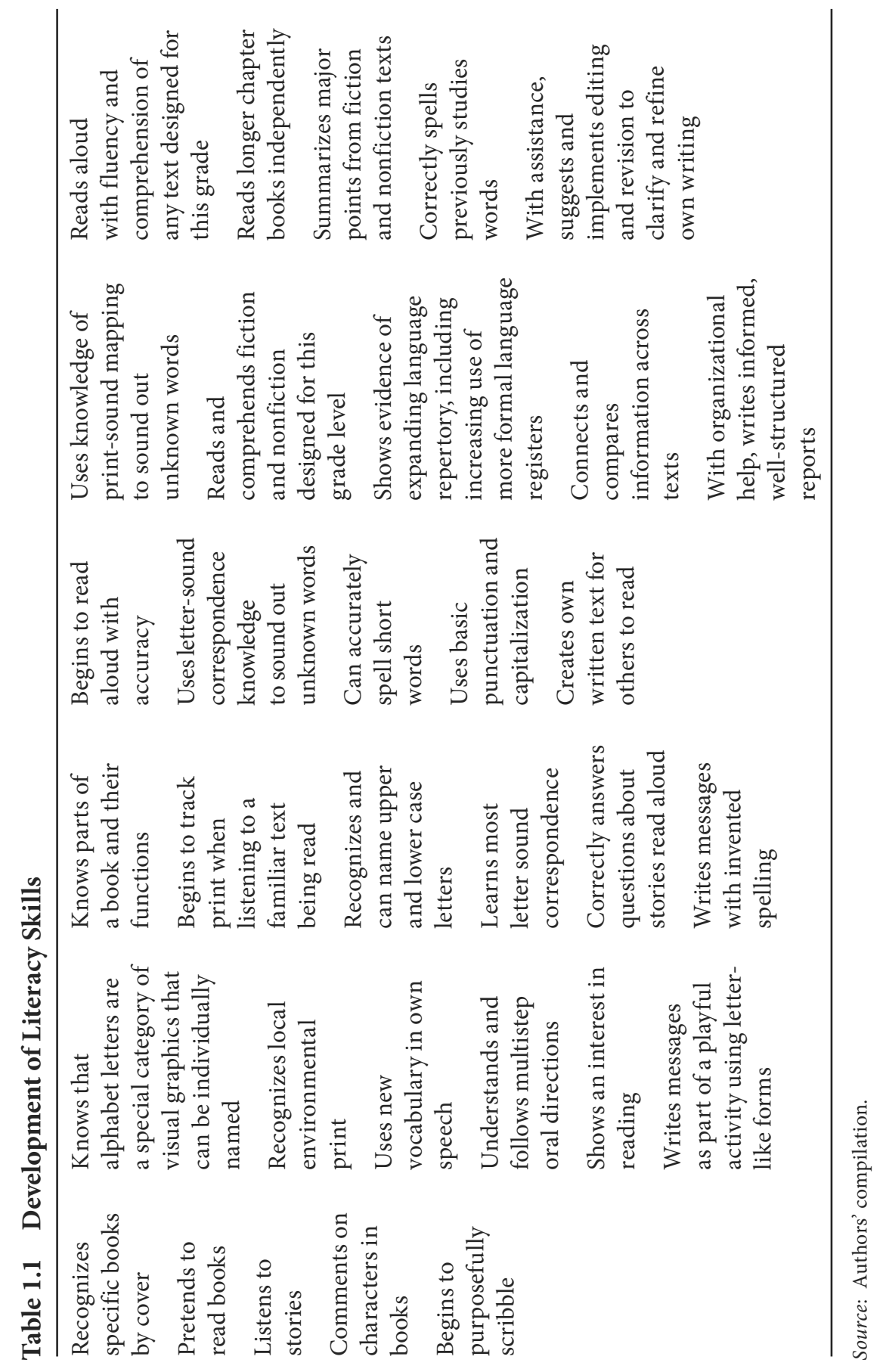


process that leads to the development of literacy skills from birth to third grade.

Cognitive skills: Cognitive skills include analytical skills, problem solving, memory, and early mathematical abilities (Johnson 1998). When children respond to their own name at about 12 months and learn to stack or nest objects at 15-18 months, they are developing their cognitive abilities on schedule. By age 3 , most children are capable of solving simple puzzles, matching colors and shapes, and also show awareness of concepts such as "more" and "less" (Kuhn and Siegler 1998). Cognitive development at school age is associated with the knowledge of letters and numbers, the ability to retain information, and the knowledge of basic information like one's name and address. Standardized tests of reasoning, problem solving, memory, and mathematical abilities at the start of school are reliable indicators of children's cognitive development and are strong predictors of scores throughout primary and secondary school (Duncan and others 2007; Duncan 2011).

How do humans control and coordinate their cognitive operations? A relatively new concept in neuropsychology named "executive function" (the ability to control impulses, initiate action, sustain attention, and persist in actions or attainment of goals) tries to address this issue. Executive function is an important determinant of how well young children adapt to and learn in school. The concept and its measurement are described in Box 1.2.

\section{Box 1.2 In a Child's Mind: Executive Function}

Executive function includes a set of basic self-regulatory skills that involve various parts of the brain, particularly the prefrontal cortex. The concept comes from neuropsychological research in the 1980s and 1990s that studied the consequences of damages to the frontal lobes. Executive function starts to develop in infancy but changes dramatically in early childhood, as the frontal lobe develops (Anderson 1998).

These abilities are distinct from cognition or knowledge of information such as vocabulary (Jurado and Rosselli 2007). Although there have been competing definitions of executive function and how 
to measure it, there is a growing consensus that executive function includes three broad domains: inhibitory control, working memory, and cognitive flexibility. Sometimes, attention is added as a separate domain.

Inhibitory control refers to the ability to suppress impulsive behaviors and resist temptations. Working memory refers to the ability to hold, update, and manipulate verbal or nonverbal information in the mind for short periods of time. Cognitive flexibility refers to the ability to shift attention between competing tasks or rules. Attention is the ability to focus and disregard external stimuli, which is why it is often grouped with working memory.

In toddlers older than 2 years, the processes most commonly cited as measurable are: working memory (e.g., holding information in mind for a short time, such as a series of numbers); inhibition of behavior or responses as demanded by the situation or task (such as not opening a box until a bell rings); and paying attention as required or being able to switch attention as necessary (such as shifting focus from the color of a stimulus to the shape of the stimulus) (Carlson 2005).

Different components of executive function can be measured separately and at different ages, but it is the ability to coordinate them to solve a problem or reach a goal that is most important to assess (Welsh, Friedman, and Spieker 2006). Executive function is an important predictor of children's learning trajectories and long-term outcomes, including in the labor market (Moffitt and others 2011; Séguin and Zelazo 2005).

Socioemotional skills: During the first two years of life, children learn whether their caregivers will respond to them and how much they can trust them. Sensitive and responsive relationships with caregivers are essential for teaching children to trust others and to deal effectively with frustration, fear, aggression, and other negative emotions (Thompson and Raikes 2007). Healthy infants and toddlers show preferential attachments to caregivers: they recognize their parents' faces at 1-4 weeks of life, smile at $4-5$ weeks, respond to parents' voices at around 7 months, and indicate their wants at 7-15 months. They are also eager to explore novel objects and spaces, and are able to reach for a toy at 4 months, play ball with a caregiver at around 10 months, feed a doll at 12 months, and play board games 
at 32 months. Finally, they enjoy initiating and responding to social interactions, such as waving bye-bye, at 7 months; imitating activities and drinking from a cup starting at 9 months; helping in the house, using a fork/spoon, and removing clothes between the first and second year of life; and brushing their teeth and washing and drying their hands between 18 and 24 months.

In the preschool years, social and emotional development expands to include children's social competence (how well children get along with other children, teachers, and adults), behavior management (ability to follow directions and cooperate with requests), social perception (how well children can identify thoughts and feelings in themselves and in others), and self-regulatory abilities (emotional and behavioral control, especially in stressful situations). All these skills are critical for children's success in school (Thompson and Raikes 2007) and throughout their lives. ${ }^{8}$

The brain plays a key role in the process of language, cognition, motor, and emotional development. Neuroscience has discovered much about the development of the brain during the past 50 years, but much has yet to be discovered. Although the connection between neuroscience and child policy is still tenuous, Box 1.3 describes some basic facts about brain development and the critical role of good early experiences in the development of the brain.

\section{Box 1.3 Early Experiences and Development of the Brain}

At the time of delivery, the baby's brain has not completed its development, although the brain's structure (which is genetically determined) is already formed. At birth, the human brain has a minimal set of connections and neural pathways. In the first three years of life, brain development is at the core of the development of a child. From birth until about age 3 , synapses in the brain develop very rapidly and efficiently. At the age of 2 years, the number of synapses in the brain of a child has reached the typical amount in an adult; at age 3 , synapses in the brain of a child (about 1,000 trillion) are double those of an adult brain. This number is maintained until about 10 years of age, at which time the synaptic density of the brain begins to decline. By the end of adolescence, only 500 trillion synapses will remain. 
Brain development can be considered a process of production and disposal of synapses. In the first three years of life, production is greater than disposal; for the rest of the first decade of life, production and disposal reach a certain balance; and upon entering adolescence, elimination is the dominant process (Bedregal and Pardo 2004).

In the brain's process of producing and disposing synapses, the individual's interaction with the environment (reaction to stimuli; collection, processing, and storage of information) plays a major role (Fox, Levitt, and Nelson 2010). Apparently, brain activity is directed by genetically configured neural patterns, while the details of such patterns (the amount and type of synaptic connections) are largely determined by the interaction with the environment (Greenough, Black, and Wallace 1987). The brain is able to modify its organization and functions according to experience-an ability known as brain plasticity (Greenough, Black, and Wallace 1987; Masten and Coatsworth 1998). When a stimulus activates a neural pathway, all the synapses that comprise that pathway will receive and store a chemical signal and will be strengthened by the repetition of that incoming signal. When the signal exceeds a certain threshold (which varies depending on the area of the brain), that synapse is exempt from elimination. Similarly, synapses that are not sufficiently reinforced by the stimulus are candidates for removal. Different regions of the brain's cortex increase their size (via the increasing number of dendrites in each neuron) when exposed to stimulating conditions; the longer the stimulation, the larger the growth of dendrites in each neuron and the larger the dendrite trees. Brain plasticity is particularly high during the first decade of life; after that, synaptic density decreases.

Recent neurological research (Weaver and others 2004; Rommeck and others 2009, 2011; Nelson, Fox, and Zeanah 2014) suggests that warm, stimulating childcare has a profound impact on brain development via the development of neural connections and patterns. For example, research on institutionalized Romanian orphans has shown that profound and prolonged neglect in early childhood is associated with lower IQ and a variety of psychiatric illnesses (including ADHD and conduct disorders). Among these children, those who were placed in early foster care showed substantial improvements relative to those left in institutionalized care, although they generally did not catch up with other children who had never been institutionalized (Nelson, Fox, and Zeanah 2014; Rutter and the ERA Study Team 1998). 
Measuring child development outcomes: Table 1.2 shows some measurable outcomes of child development, including examples of the most widely used instruments. Child development assessments are usually based on four domains-physical development, language/communication, cognitive skills, and socioemotional skills. However, there is no consensus on a single measure for assessing the development of a child (such as height-for-age standard scores for physical development); therefore, the table presents the most used instruments in the literature (in parenthesis). For example, the Peabody Picture Vocabulary Test (PPVT) is a validated and widely used test to measure language in children, while the Bayley Scales of Infant Development (BSID) measures cognition, language, motor, and socioemotional outcomes. Further details on each instrument are provided in Box 1.4.

\section{Table 1.2 Outcomes by Developmental Stage and Examples of Associated} Measures

\begin{tabular}{ll}
\hline Antenatal/natal/neonatal & Early childhood \\
\hline - Fetal development (weeks of & - Morbidity and mortality of infants and \\
gestation, birth weight, birth & children \\
length, and head circumference) & - Physical development (length/height- \\
- Morbidity and mortality of & for-age, weight-for-age, and head \\
newborns & circumference) \\
- & Cognitive development (e.g., Bayley Scales \\
& of Infant Development [BSID], Wechsler \\
& Inventories, the Denver Developmental \\
& Screening Test) \\
- Language development (e.g., Peabody & Picture Vocabulary Test, BSID) \\
- Executive function (e.g., tests of & inhibition, working memory, attention) \\
- Fine and gross motor (e.g., Ages and & Stages Questionnaires, BSID, Denver \\
& Developmental Screening Test) \\
- & Socioemotional development (e.g., Denver \\
& Developmental Screening Test, BSID) \\
- School performance and learning & (e.g., math and literacy standardized \\
& achievement tests scores) \\
&
\end{tabular}

Source: Authors' compilation. 


\section{Box 1.4 Measuring Child Development}

Many instruments have been designed to measure child development. Child development tests can be divided into two broad categories:

a. Diagnostic tests are designed to provide a detailed assessment of the developmental level of a child. They are characterized by psychometric properties of sensitivity (and specificity), meaning that they accurately identify (and rule out) children at risk (not at risk) of a developmental delay. They are also characterized by properties of validity (face validity, concurrent and predictive validity) and reliability (internal consistency, test-retest). Diagnostic tests are administered by specialized psychologists with training in the use of these instruments. Their administration is usually lengthy, and it combines the direct observation of children and parental reporting. The Bayley Scales of Infant and Toddler Development or the Complete Battelle Developmental Inventory are examples of diagnostic tests that have been administered to large evaluation samples in countries like Chile, Colombia, Mexico, and Peru.

b. Screener tests are designed to identify at-risk children, and therefore, their properties focus more on their sensitivity than on their specificity. Clinically, they are most often used as a first stage in a process of a developmental diagnostic. Screeners are simpler to administer. They contain fewer items than diagnostic tests. They tend to rely more on parental reporting than on direct observation of the child. The Ages and Stages Questionnaire (ASQ), the Screening Test of the Battelle Developmental Inventory, the Denver Developmental Screening Test, the Nelson Ortiz Scale, and the Prueba Nacional de Pesquisa PRUNAPE are examples of screeners that have been administered to large evaluation samples in Argentina, Brazil, Colombia, Ecuador, Honduras, Mexico, Nicaragua, and Peru.

Developmental tests often assess multiple dimensions of child development, such as cognition, receptive and expressive language, fine and gross motor development, socioemotional development, and adaptive behavior. This is the case of tests like the Bayley, the Battelle, the Denver, or the ASQ. There are also tests designed to focus on one particular developmental area. For example, the MacArthur Bates 
Communicative Development Inventories are designed to assess receptive and expressive language in children younger than 3 years of age; the Strengths and Difficulties questionnaire is a screener test for behavioral problems-emotional, attention, conduct, relationships, and prosocial behaviors - for children as young as 3 years of age.

There is no consensus on which is the best child development test. The choice of a test depends on many elements, among others, the purpose and scale of the measurement, the age of the child, and the resources available (time, money, and personnel) to carry it out. Diagnostic tests have been administered in large samples as part of evaluations aimed at measuring the impact of programs. Screener tests have also been added to household surveys to measure the impact of policy interventions. Aggregated at the classroom level, screener test scores have also been used to monitor provider quality. Not all developmental tests are designed to cover the same age ranges. The Bayley can be used from birth to 42 months of age, while the Battelle covers children up to age 7, the ASQ up to age 5, and the Denver up to age 6.

\section{Child Experiences: The Stories That Make the Person}

When human beings become embryos, their complete genetic makeup is determined. The individuals they turn out to be is the consequence of the interaction between this genetic makeup and their life experiences. In a few cases, life experiences have no bearing on some important features, such as sex. In most cases though, the path is highly uncertain and strongly dependent on life experiences.

Mounting causal evidence indicates that early experiences often have persistent, long-lasting, and significant effects on a wide array of important youth and adult outcomes. First, since developing countries have few mechanisms to cope with risk, environmental and economic shocks-such as severe weather, epidemiological events, or armed conflict-can generate long-lasting negative effects, usually by way of their impact on nutrition. ${ }^{9}$ For example, Maccini and Yang (2009) look at the effect of rainfall in the Philippines; Almond (2006) studies the persistent impact of the Spanish influenza of 1918 in the United States; and Akresh and others (2012) analyze the effect of growing up during the Nigerian civil war. 
Second, the behavior of parents, the daycare center their children attend, and early schooling experiences (all of them central issues of this book) also have long-lasting impacts. For example, a 20 -year follow-up (Gertler and others 2014) of a randomized experiment in Jamaica, where the mothers of malnourished children were encouraged to play with their 9- to 24-month-old children, found that those who received the stimulation intervention eventually had earnings around 25 percent higher than those in the control group. ${ }^{10}$ Children from low-income families randomly assigned in the 1970s to highquality childcare in Chapel Hill, North Carolina, in the United States (Campbell and others 2001,2014) were less likely to drop out from high school and more likely to attend a 4-year college at age 21. Berlinski, Galiani, and Manacorda (2008) used the dramatic expansion of pre primary education in Uruguay during the 1990s to look at how participation in preprimary education affected the completion of school grades. At age 15, those who attended preprimary education had completed 0.8 years of education more than those who did not attend.

Finally, the education received in the very first years of schooling also has long-term effects. Chetty and others (2011) look at the longterm impact of Project STAR (Schanzenbach 2007), an experiment conducted in the US state of Tennessee in the mid-1980s, to evaluate the effect of smaller class sizes. Students assigned to smaller classes were significantly more likely to attend college and exhibit improvement in an index that combines information on savings behavior, home ownership, marriage rates, mobility rates, and residential neighborhood quality. ${ }^{11}$ Also, conditional on classroom assignments, students who had a more experienced teacher in kindergarten had higher earnings.

Experiences in the early years are shaped by the interactions between the child and various caregivers. These interactions occur simultaneously in four different environments: the home, the daycare center, the school, and the community. ${ }^{12}$ Home and community are always central to an individual's experiences. This is particularly salient during the early months of life. As children grow, some of the care they receive may begin to occur outside their homes, in institutions such as daycare centers. Most children move into primary schools when they reach school age. 
In these environments, children interact directly with many caregivers (parents/guardians, family members, family friends, and teachers) who have different resources available to them. Examining the key aspects that determine these interactions reveals the potential role for public policy.

\section{It All Starts at Home}

Parents and guardians make an infinite number of choices (consciously or unconsciously) that determine children's experiences in the early years of life. They start by choosing when and how to bring them into this world. Then, they decide what and when to feed them, where they will live, and what clothes they should wear. They also make choices about when to take them to the doctor and whether to follow their advice. They make nonmaterial decisions, such as whether to raise them in a nuclear family, how and when to talk to them, and how to encourage acceptable behavior and discourage unacceptable reactions. Of course, they may also decide to delegate some of the caring time to daycare centers, schools, or directly to other people, such as relatives or nannies.

This is a complicated set of choices for parents to make, and it is complicated for those interested in child development to understand. Ultimately, however, if the objective of public policy is to affect choices and child development outcomes, it is useful to provide a framework to interpret the determinants of these choices. Economists, for example, characterize this problem as one in which parents are trying to fulfill their needs and the needs of those they care about subject to two constraints (Becker 1981, 1993). First, parents are constrained by how the resources they spend (time and money) translate into what they want for their children. Second, the cost of fulfilling these needs cannot exceed the resources available to cover these costs. These concepts are discussed in more detail in the paragraphs that follow.

Start with preferences. Human decisions are driven by the desire to fulfill one's own needs and those of others one cares about. Various dimensions of needs are important to consider when looking at the decisions parents make. The first dimension is a temporal one. 
How much are parents willing to trade off the satisfaction of current versus future needs; that is, how impatient are parents? This factor is important, as many of the decisions parents make on behalf of their children involve current sacrifices in exchange for future rewards. Crucially, parents make the sacrifices, and many of the benefits are likely to be reaped by the children as adults, which prompts the second dimension. How much do parents care about the needs of others and, in particular, of their children; that is, how altruistic are parents? This consideration leads to the first rationale for policy intervention: parents may not value future outcomes as much as society as a whole (they may be too impatient) or they may not be willing to make the sacrifices that will result in the optimal allocation of resources for society (they may not be altruistic enough).

Within a given set of preferences, the choices that parents make are subject to two main constraints. The first one is technology; for purposes of this analysis, technology can be considered the process that governs the transformation of experiences and genetic make-up into child development outcomes. Experiences depend on resources (such as time and money) allocated by individuals. For example, if the outcome is language acquisition, the inputs are "conversations/ talk time," books, and the time devoted to reading.

Experiences also depend on many factors outside parents' control such as the disease environment or the decisions of others (e.g., governments). Experts in child development usually call experiences that may have a negative impact on development "risk factors" and those with a potentially positive impact "protective factors." The impact of experiences on development may be complex; for example, a child may have to suffer many developmental insults for them to have a negative impact.

With child experiences, as with so many things, timing is everything. At the core of the definition of "developmental milestones" is the idea that stages of development occur during predictable time periods. Child development specialists have long studied whether there are sensitive periods for physical and skills development and, therefore, whether technology is age-dependent. ${ }^{13}$ Nobel Prizewinning economist James Heckman, among others, has argued that there might be a sensitive age range in which acquiring a given skill 
requires fewer resources or the absence of some experience may have permanent developmental consequences.

A classic example of a sensitive age range refers to the acquisition of vision. Nobel Prize winners David Hubel and Torsten Wiesel (Wurtz 2009) conducted experiments with cats and showed that if the animal is deprived of a normal visual experience during a critical period at the start of its life, the circuitry of the neurons in its visual cortex is irreversibly altered. Conversely, if the eye of an adult cat is deprived of vision, the responses of the cells in its visual cortex remain identical to those of a normal cat. This is why it is so important to detect vision problems early in life; otherwise, the ability to see and learn visually can be impaired permanently.

How resources translate into outcomes depends on innate and accumulated traits of children. If the child has hearing problems, her ability to acquire language through speech is impaired. Interestingly, children who are known to be deaf and learn through sign language exhibit no problems acquiring language or learning to communicate. Moreover, the more children are spoken to, the more language they know; therefore, talking more to them may allow them to acquire language in subsequent periods at even faster rates. This relation between early accumulation and later outcomes is described in economics by the concept of dynamic complementarities (Cunha and Heckman 2007; Heckman 2008). Dynamic complementarities and sensitive age periods imply that the timing of interventions, by parents, caregivers, or public policy operators, may also be important.

This complex dynamic relation is one of the main reasons behind the second rationale for policy intervention: parents may not make the best decisions on behalf of their children because they are ill informed about the relationship between experience and outcomes; that is, they have imperfect information. For example, they may think toddlers' tantrums (something biologically natural at this age) are an expression of bad behavior and try to elicit appropriate behavior by hitting them. Of course, systematic failures in parental behavior are not linked only to lack of knowledge; there may be other contributing factors such as parental stress, depression, and lack of self-control. 
The second constraint relates to the cost and availability of resources. Producing experiences and generating outcomes is costly. Costs include the time and resources allocated by individuals over time, including all the early years of a child's life and beyond. Costs, therefore, can be current, occurring in the present: for example, a sick day that a mother takes to care for her sick child, or the current expense of a book or toy she buys for them. Other costs are experienced only in the future. For example, a child with cataracts who is not treated early on is likely to develop serious eyesight problems. This will create health care problems in the future, reducing her well-being and her productivity as an adult.

Of course, parents can only spend the money they currently have or that they can borrow. Frequently, the lack of money and resources create a binding constraint to increasing the investment in children to the desired level. The problem could be solved if capital markets were able to provide parents with resources today in exchange for some of the returns in children's investment that will be realized in the future. If capital markets can provide this only imperfectly (only partially or to a subset of families), then constraints in the access to credit generate a third rationale for policy intervention.

In many circumstances, the costs of resources are not borne exclusively by parents, and the benefits are not enjoyed solely by them and their children. This leads to what economists call "externalities" (negative or positive). Suppose, for example, that a parent fails to vaccinate her child against a preventable disease-an action that can be completed at a relatively low cost for the individual. If the child becomes sick because she was not vaccinated, and the associated health care costs and negative long-term consequences are completely borne by the individual, then there are no negative externalities. However, if society shares some of the short- and long-term costs of the disease, either in terms of medical outlays or by increasing the chance of illness for those that cannot be vaccinated, then the parent is imposing a negative externality on society. The presence of negative or positive externalities generates the fourth rationale for policy intervention.

Finally, the process that leads to parental choice is neither deterministic nor static. In particular, parents must contend with 
uncertainty about three fundamental aspects: their child's initial endowment, how their actions translate into outcomes, and the long-term benefits of investing in their child's development. They hold beliefs about all three aspects. Because parents update their beliefs with the arrival of new information, the process of child rearing is naturally a dynamic one. For example, in Puebla, Mexico, parents of 10-year-old children had incorrect perceptions about how overweight or obese their children were (Prina and Royer 2014). Distributing report cards featuring their child's body weight increased parental knowledge and shifted parental attitudes about children's weight. ${ }^{14}$

\section{Daycare Centers: The Second Line of Care}

When the main care providers for a child decide to work, they must pursue alternative modes of childcare for their children. In urban and semi-urban areas of Latin America and the Caribbean, parents increasingly rely on daycare centers. Government support for the expansion of daycare centers has been historically associated with offering public incentives for women to look for work (Araujo and López Boo 2015). In Latin America and the Caribbean, daycare services are delivered through different institutional arrangements: private providers, private/community providers with partial subsidies from the state, and public providers.

In choosing a childcare provider parents must balance convenience, price, and quality of care (Blau and Currie 2006, 2008). Convenience is reflected in the distance to their house or their job and the hours of operation of the center. There is evidence from developed countries that prices (e.g., Baker, Gruber, and Milligan 2008; Havnes and Mogstad 2011) and convenience (e.g., Neidell and Waldfogel 2009) are important determinants of daycare choice. However, how the well-being of children is affected by attending a daycare center instead of being cared for by their parents or other childcare providers at home hinges crucially on the quality of care. This is true even when taking into account the additional resources that are available to the households if parents are working (Bernal and Keane 2011). 
How is quality determined? The institutional arrangement for the provision of services influences the quality of services that are offered. Childcare services are what economists call an experience good $^{15}$ (a good whose quality consumers are likely to ascertain only after consuming it). The main issue in this environment is information: How do parents determine the quality of a childcare provider when it may take a long time to determine quality or negative experiences may have long-term consequences? What incentives do the providers have to offer high-quality services?

In private markets, prices may provide some signals about quality. Economic research (Tirole 1988) has shown that where direct information can be obtained (even at a cost), informed consumers can improve the quality of the products offered. Moreover, as the fraction of well-informed parents increases, the likelihood that valuable information will be revealed increases as well. As a result, the public benefit of an informed parent is greater than the private cost the parent is willing to pay. This positive externality provides a rationale for public policy intervention in the childcare market. Standards and licensing systems guaranteeing minimum levels of quality could be seen as an answer to this need. Parents know that a licensed childcare center provides at least that minimum level of quality.

However, imposing a minimum level of quality has its limitations. Enforcing regulation is very difficult and costly because this is a market with many small providers. Even assuming perfect enforcement, regulating the minimum quality may not generate the variety of quality demanded by parents. If the standard is too low, the market may offer too many providers close to the minimum quality, leaving the demand of parents willing to pay for a higher standard unsatisfied. If the standard is too high, the total supply of childcare services may be too low to satisfy demand, particularly for lowincome parents, which may drive them to a completely unregulated sector (Hotz and Xiao 2011).

Subsidized childcare provision or voucher programs cannot solve the information gap issue. However, voucher programs may be effective in changing the average quality at which demand and supply meet because they allow parents to buy more expensive care. Importantly, a combination of vouchers and regulation of private 
providers may prevent some parents from moving to the unregulated sector after regulation is introduced. ${ }^{16}$

\section{Schools: A Common Denominator}

In Latin America and the Caribbean, primary school education from around age 5 is compulsory, publicly provided, and mainly free. Enrollment in primary school from age 6 onward has been virtually universal across most countries since the 1990s. The emphasis on parental choice is therefore very different in the case of primary school compared to daycare. Parents have fewer choices in this case because they must send their children to school and frequently cannot choose which public school their children will attend. ${ }^{17}$

The core objective of the primary school system is to help children achieve appropriate levels of literacy, numeracy, and socioemotional competencies. Going back to the relationship between experience and technology, the evidence shows that the process of acquiring academic skills is only loosely age dependent. Although starting too early or too late may be costly, reaching a satisfactory level of literacy and numeracy is feasible at almost any age, and the age interval during which the cost of acquisition is very similar and relatively low is quite large. For example, Finland, a country routinely ranked at the top of children's achievement indicators, starts compulsory teaching of literacy and numeracy at age 7, two years later than the average in the Latin American and Caribbean region.

From an organizational point of view, it is crucially important for a given country or very large community to determine a common school age. This coordination is necessary because it is far less expensive to teach a relatively large number of children who are similar in terms of their knowledge and maturity than it is to teach oneon-one or children with very different backgrounds and at different stages in their development. A universal school entry age and the grouping of children in school by age is an institutional arrangement that makes school readiness a critical issue. If children are not ready for school at age 5, they may easily fall behind, generating the need for expensive remediation interventions. Moreover, a high proportion of children lacking school readiness may negatively affect the 
learning of children who are ready for school. The possible negative externality, together with the need to agree on a school entry age, provides a rationale for public policy intervention before children reach primary school.

\section{The Policy Toolkit}

Public policy should enhance children's lives from the time of their conception until well after they enter school. Before they begin the compulsory education process, children are molded mainly in their homes and in daycare centers. The challenge for public policy is to adopt an integral view of this development process (see Chapter 7).

Policymakers have at their disposal five main instruments to affect child outcomes and parental decisions: information and coaching (e.g., awareness campaigns, coaching mothers on breastfeeding), laws (e.g., parental leave, compulsory education at a given age), regulations (e.g., regulation of advertisements about baby formula, regulation of child-to-staff ratios in daycare centers), transfers (e.g., universal child transfers, tax credits, conditional cash transfers), and prices (e.g., subsidized childcare, free vaccination).

Governments may use a combination of these instruments to achieve their objectives (Carneiro and Heckman 2003). For instance, to ensure a well-educated population, they can make education compulsory at a given age, regulate class sizes and teaching standards, give parents a transfer conditional on taking children to growth and development check-ups and on school attendance, and provide free schooling. The combination of instruments should be dictated by the perceived difficulty of individuals and markets in achieving the stated objectives.

The government acts as the main or sole provider of services (e.g., childcare, education, health) in many areas crucial to the well-being of children in the early years. Given a fixed government budget, a key trade-off in the provision of these services is the relationship between quantity and quality. The government may understandably try to reach as many children as possible. However, with a fixed budget, serving more children implies less expenditure per capita. Many of the services provided by the public sector are experience 
goods (like the provision of daycare) and the government may have an incentive to provide low quality when this is hard to spot by consumers/voters. Clearly, this decision is not without consequences; it may not only waste money but potentially harm the well-being of children-particularly, those from the neediest sectors of society that cannot afford to obtain services elsewhere.

Child well-being results from a cumulative, nonlinear process of child development that encompasses four main areas: physical development, language/communication, cognitive skills, and socioemotional skills. This process of development does not unfold on its own, but is shaped by the experiences children accumulate at home, in daycare centers, and at school. Parents, relatives, other caregivers, teachers, and government all have a hand in shaping those experiences. Improving those experiences will shape children's lives and the face of the societies they live in for years to come. Clearly, child well-being matters for both ethical and economic reasons and public policy has a role to play in developing happy, healthy, and prosperous children.

(c) (i) $(-)$ Except where otherwise noted, this work is licensed under a BY NC ND Creative Commons Attribution-NonCommercial-NoDerivatives 3.0 IGO License. To view a copy of this license, visit https://creativecommons. org/licenses/by-nc-nd/3.0/igo/ 